Maciej KOKOSZKO

(Łódź, UŁ)

\title{
SOSY W KUCHNI GRECKIEJ. GARUM (IAPOE) I POCHODNE
}

Kuchnia grecka miała do swej dyspozycji wiele dodatków do potraw, wśród których niepoślednią rolę obejmowały także sosy. Modyfikowały one smak mięsa i warzyw oraz często stanowiły o wartości dietetycznej całej potrawy. Były to zarówno sosy zimne, jak i gorące (przygotowywane specjalnie z myślą o danej potrawie). Wiele spośród nich sporządzano w oparciu o tak zwane garum (үó@os).

Na początku pragnąłbym poczynić kilka uwag ogólnych dotyczących zawartości prezentowanego artykułu. Po pierwsze, praca niniejsza zawierać będzie jedynie informacje o sosach, w których termin garum stanowił część ich nazwy. Nie wszystkie zatem tego typu dodatki uwzględniające w swej recepturze garum będą przedmiotem moich obecnych rozważań. Po drugie, artykuł niniejszy, choć stara się naszkicować terapeutyczne działanie garum, nie zawiera pełnej analizy jego wartości leczniczych. Zagadnienie to jest, wedle mej wiedzy, na tyle szerokie i skomplikowane, iż rezerwuję dla siebie tę kwestię do całościowego opracowania w najbliższej przyszłości. Po trzecie, artykuł niniejszy nie zawiera szczegółowych rozważań co do skali produkcji garum, centrów jego wytwarzania, szczegółów technicznych tego procesu etc. Wychodząc z założenia, iż zagadnienia te zostały już opracowane w wystarczającym zakresie, a nadto chcąc uniknąć cytowania bardzo obszernej literatury tego dotyczącej, odsyłam czytelników do mojej niedawno opublikowanej pracy dotyczącej ryb w źródłach antycznych i bizantyńskich, gdzie podstawowe dzieła $z$ tej dziedziny zostały zacytowane ${ }^{1}$.

Garum był to sos powstały na drodze zasolenia całych ryb lub/oraz ich wnętrzności. Stosowane było samodzielnie albo jako przyprawa uzupełniająca aromat innych produktów. Popularność swą zyskało ok. V wieku przed Chrystusem $^{2}$, a znane jest aż do dzisiaj. W języku łacińskim w stosunku do tej samej

${ }^{1}$ Por. M. Kokoszko, Ryby i ich znaczenie w życiu codziennym ludzi późnego antyku $i$ wczesnego Bizancjum (III-VII w.), Byzantina Lodziensia 9, Łódź 2005, 373-374.

${ }^{2}$ Por. A. Dalby, Food in the Ancient World from A to Z, London - New York 2003, 156. 
przyprawy używano najczęściej terminu liquamen. Nazwy allec i hallec odnosiły się do poszczególnych rodzajów ${ }^{3}$ tego produktu. Odznaczały się one niższą jakością niż garum/liquamen ${ }^{4}$. W czasach antyku i Bizancjum istniało wiele odmian tego sosu. Należy wnosić, iż różniły się one w zależności od miejsca i receptury zastosowanej przy jego produkcji. Ze źródeł wynika, iż wykształciły się trzy najważniejsze centra wytwarzania tej przyprawy ${ }^{5}$. Były one tożsame

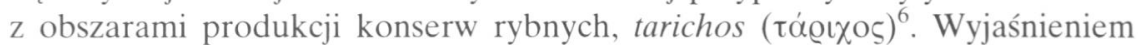
tego faktu jest ścisły związek między wytwarzaniem obu produktów. Zarówno garum, jak i tarichos wymagały stosunkowo bogatych zasobów ryb, najlepiej z rodziny Scombridae. Jeżeli przy wytwarzaniu konserw rybnych używano wyłącznie ich mięsa, to producenci sosu wykorzystywali odpady powstałe przy produkcji (zwłaszcza wnętrzności i mniej wartościowe, na przykład ze względu na wymiary lub świeżość, egzemplarze). Nadto, obie dziedziny opisywanej wytwórczości wymagały soli ${ }^{7}$. Najsłynniejszym gatunkiem garum było tzw. garum sociorum ${ }^{8}$, produkowane $\mathrm{w}$ południowej Hiszpanii z ryb skombros (бхо́ $\beta \varrho о \varsigma)^{9}$. Miało ono postać złotawego, przezroczystego płynu o charakterystycznym, mocnym zapachu oraz wyraźnie słonym smaku.

Jeżeli chodzi o warianty recepturalne, to do naszych czasów zachowało się ich kilka. Najbardziej wyczerpującym w tym względzie źródłem jest Geoponi$c a^{10}$. Dzieło to zawiera w sumie trzy różne przepisy na garum; dwa z nich, jak można sądzić, stosowano przy produkcji sosów przeznaczonych na sprzedaż, trzecia wydaje się zaś przepisem mającym zastosowanie w gospodarstwie domowym $^{11}$.

Pierwsza z wymienionych receptur przedstawia się następująco: do dużego naczynia ceramicznego wkładano wnętrzności ryb i zasypywano je solą. Na-

${ }^{3}$ Były to frakcje powstałe w wyniku oczyszczania gotowego produktu, por. poniżej.

${ }^{4}$ Hallec nie był przezroczysty z powodu zanieczyszczeń w nim pozostających, por. receptury cytowane ponizej.

${ }^{5}$ Hiszpania, Italia i Sycylia oraz obszary nad Morzem Czarnym. Wybrana literatura na ten temat por. Kokoszko, Ryby, s. 343-344.

6 Por. M. Kokoszko, Kuchnia i dietetyka późnego antyku oraz Bizancjum. Kilka uwag na temat spożycia, sporzadzania, przyrządzania, wartości dietetycznych i zastosowań medycznych konserw rybnych $w$ antycznej i bizantynskiej literaturze greckiej, w: Historia Bizancjum, red. W. Ceran (= Acta Universitatis Lodziensis, Folia Historica 80), Łódź 2005, 7-25; tenże, Ryby, s. 317-329.

${ }^{7} \mathrm{Na}$ temat zasobów tej ostatniej por. A. Jodłowski, Saliny i kopalnie soli w państwach starożytnych strefy śródziemnomorskiej, , Meander” 32 (1977) 40-53.

${ }^{8}$ Wybrana literatura na ten temat por. Kokoszko, Ryby, s. 374.

${ }^{9}$ Makrele.

${ }^{10}$ Por. Geoponica sive Cassiani Bassi Scholastici de re rustica eclogae, rec. H. Beckh, Lipsiae 1895 (dalej-Geoponica). Jest to traktat na temat rolnictwa w dwudziestu księgach, który powstał w X wieku, por. W. Gemoll, Untersuchungen über die Quellen, den Verfasser und die Abfassungszeit der Geoponica, Berlin 1883, passim; Kokoszko, Ryby, s. 14.

11 Por. Geoponica XX 46. Ciekawą interpretację tych receptur por. M. Grant, Roman Cookery. Ancient Recipes for Modern Kitchens, London 2002, 29. 
stępnie dodawano całe ryby, najczęściej małe, na przykład stynki, szproty, małe barweny oraz sardele. Zresztą wszystkie niewielkie ryby nadawały się jako surowiec do tego sosu. Na tę kolejną warstwę wysypywano jeszcze jedną porcję soli, a następnie naczynie wystawiano na słońce. Gdy rozpoczął się już proces fermentacji ${ }^{12}$, należało naczyniem często i energicznie wstrząsać. Kiedy zawartość garnka przestała się w końcu burzyć, garum było w zasadzie gotowe. Teraz należało jedynie przecedzić płyn. Wszystko to, co przeleciało przez sito, było właściwym, dobrej jakości garum (liquamen). To, co pozostało na sicie, nazywano allec (hallec). Była to gęsta substancja o podobnych do liquamen wartościach smakowych i zapachowych.

Drugi z przepisów przekazanych przez autora Geoponica nawiązuje do lokalnych sposobów wytwarzania tej przyprawy w Azji Mniejszej. W Bitynii, mianowicie, do sporządzania tej przyprawy używano zwykle ryb takich, jak szprotki, sardele, ostroboki i makrele. Wkładano je zrazu do dużego naczynia, zwykle do koryta podobnego w kształcie do ówczesnej dzieży. Na jeden modius ${ }^{13}$ ryb dodawano dwa italskie sextarii ${ }^{14}$ soli, a potem ryby i sól mieszano razem i pozostawiano na noc. Następnie zawartość dzieży przekładano do umieszczonego w nasłonecznionym miejscu naczynia ceramicznego. Z przepisu wiemy, iż powinno ono pozostać odkryte, a jego zwartość wymagała co pewien czas przemieszania. Po dwu, trzech miesiącach, gdy płyn przefermentował, a garum było gotowe, naczynie należało zamknąć i schować w zacienionym miejscu. Wiemy też, iż przepis ten był niekiedy modyfikowany w ten sposób, że na każdy sextarius ryb dodawano dwa sextarii wina. Zapewne ta ostatnia wersja odpowiadała bardziej wyszukanym gustom i była kosztowniejsza.

Trzecia receptura to przepis na domowe garum. Był to sposób przygotowania właściwy dla tych, którzy nie mieli zbyt wiele czasu, by czekać na wyniki procesu fermentacji. Wpierw należało sporządzić roztwór soli. Tej ostatniej powinno być w nim tyle, by jajko wrzucone do solanki utrzymywało się na powierzchni. Następnie przelewano roztwór do nowego, ceramicznego naczynia, dodawano ryby i nieco oregano ${ }^{15}$. Garnek stawiano na ogniu, zawartość doprowadzano do wrzenia i gotowano, aż do momentu, gdy ilość płynu zaczynała wyraźnie się zmniejszać. Niektórzy, oprócz wymienionych powyżej skład-

12 A może raczej hemolizy.

13 Modius $=8,733$ litra.

14 Sextarius $=0,545$ litra.

15 Oregano = Origanum vulgare, L. Charakterystyka tej rośliny: Aetii Amideni liber I 302, 104, w: Aetii Amideni libri medicinales I-VIII, ed. A. Olivieri, Lipsiae - Berolini 1935-1950, I, 302, 1-4 (dalej - Aetius Amidenus, Iatricorum libri). Wybrana literatura nowożytna: A. C. Andrews, Marjoram as a Spice in the Classical Era, CPh 56 (1961) 73-82; J. André, L'alimentation et la cuisine à Rome, Paris 1961, 205; L. Bremness, Wielka księga ziót, tłum. J. Cieśla - W. Jackowska R. Jackowski i inni, Warszawa 1991, 104-105; Dalby, Food, s. 243-244; Leksykon roślin leczniczych, red. A. Rumińska - A. Ożarowski, Warszawa 1990, 260-261 (dalej-Leksykon roślin); T. Stobart, Herbs, Spices and Flavourings, London 1998, 139-140; por. takze Kokoszko, Ryby, s. 377-378. 
ników, dolewali do wywaru zagęszczonego moszczu winnego ${ }^{16}$. Potem odstawiano naczynie z ognia i pozostawiano do ostygnięcia. Zawartość przecedzano dwa lub trzy razy, aż stała się przezroczysta. Następnie przelewano gotowe garum do naczynia z pokrywką.

Garum było produktem, którym handlowano na całym obszarze nad Morzem Śródziemnym; osiągało wysokie ceny i - w związku z tym - nie było przyprawą powszechnie dostępną ${ }^{17}$. Sos ten stawiano na stole, by jedzący mogli sobie sami doprawić potrawę poprzez skropienie ${ }^{18}$ lub zanurzenie jej w przyprawie ${ }^{19}$. W wykwintnej kuchni greckiej i rzymskiej sos rybny dodawany był także do większości potraw mięsnych i rybnych, oraz do znacznej liczby potraw mącznych. Zastępowało ono sól i dodawało koloru potrawom. Użycie garum jest wielokrotnie zaświadczone we fragmentach zachowanych w Deipnosofistach Atenajosa z Naukratis, w De re coquinaria ${ }^{20}$ oraz w antycznych i bizantyńskich źródłach medycznych. Garum było także podstawą do produkcji sosów pochodnych. Chodzi zwłaszcza o garelaium, garelaion ( $\gamma \alpha \varrho \varepsilon ́ \lambda \alpha \iota v)$,

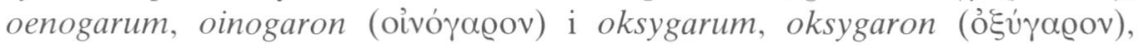
o których będzie mowa później.

Medycyna przypisywała garum pewne właściwości lecznicze. Są one szczegółowo opisane na kartach pism medyków greckich, na przykład Pedaniusza Dioskuridesa, Galena, Aecjusza z Amidy i Pawła z Eginy ${ }^{21}$. Rzeczeni

${ }^{16}$ Gotowany moszcz winny zredukowany do konsystencji syropu. Najczęściej używana nazwa

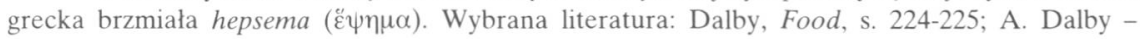
S. Grainger, The Classical Cookbook, London 2000, 24-25; B. Flower - E. Rosenbaum, Introduction, w: The Roman Cookery Book. A Critical Translation of ,The Art of Cooking” by Apicius for Use in the Study and the Kitchen by B. Flower - E. Rosenbaum, London - Toronto - Wellington Sydney 1958, 23-24; P. Garnsey, Food and Society in Classical Antiquity, Cambridge 1999, 139; I. Gozzini Giacosa, A Taste of Ancient Rome, translated A. Herklotz, foreword M.T. Simeti, Chicago - London 1992, 29-30; J. Solomon, The Apician Sauce. Ius Apicianum, w: Food in Antiquity, ed. J. Wilkins - D. Harvey - M. Dobson, Exeter 1995, 115-131, spec. 119-124 i 130, nota 40; por. także Kokoszko, Ryby, s. 372.

17 Chodzi zwłaszcza o uznane jego gatunki.

18 Archestratos oraz autor leksykonu zwanego Księgą Suda nazywał podane w ten sposób

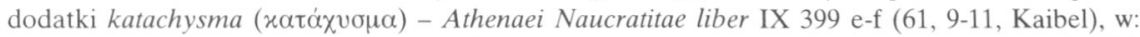
Athenaei Naucratitae dipnosophistarum libri XV, rec. G. Kaibel, vol. I-III, Lipsiae - Berolini 1887 1890 (dalej - Atenaeus Naucratita, Dipnosophistarum libri); Suidae Lexicon, rec. A. Adler, I-IV,

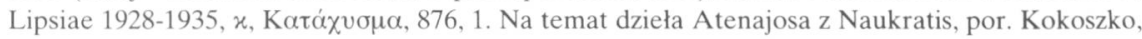
Ryby, s. 10-12.

${ }^{19}$ Garum mogło zatem być zaliczane do kategorii dodatków zwanej embamma ( $\left.\varepsilon \mu \beta \alpha \mu \mu \alpha\right)$. Ten ostatni termin określał sosy, w których zanurzano gotowe potrawy, por. np. Athenaeus Naucratita, Dipnosophistarum libri IX 404 d (68, 40-42, Kaibel).

${ }^{20}$ Por. Apicii librorum $X$ qui dicuntur De re coquinaria quae extant, ed. C. Giarratano F. Vollmer, Lipsiae 1922, tłum. i komentarz I. Mikołajczyk - S. Wyszomirski: Apicjusz, O sztuce kulinarnej ksiąg dziesięć, Toruń 1998 (dalej - Apicius, De re coquinaria). Dzieło napisane w 2. poł. IV lub na początku V wieku; na jego temat por. Kokoszko, Ryby, s. 19-20.

21 Wymienieni autorzy byli praktykami i teoretykami medycyny, por. Kokoszko, Ryby, s. 12-16. 
znawcy medycyny podkreślali zwłaszcza, iż ułatwiało ono trawienie ${ }^{22}$. Ciekawe jest, że w wymienionych powyżej dziełach zachował się prawie zgodnie brzmiący rozdział o właściwościach garum. Charakteryzowano tam ten sos jako substancję o silnych właściwościach rozgrzewających oraz wysuszających. Dlatego też używano go (zewnętrznie) do leczenia długo niegojących i jątrzących się ran, w przypadkach (wewnętrznie) dyzenterii oraz (zewnętrznie) isjaszu ${ }^{23}$.

Gdy chodzi o przepisy na sosy, które zawierały garum jako najważniejszy swój składnik, źródła zachowały kilka interesujących szczegółów. Wynika z nich, że specyfiki takie miały nie tylko swoje zastosowanie kulinarne, ale (jak samemu garum) niekiedy przypisywano im również właściwości lecznicze. Takim sosem było garum oczyszczające, garos katharktikon ( $\gamma \alpha \dot{\alpha}$ $\theta \alpha \varrho \tau \iota x o ́ v)$, recepturę którego zachowały Iatricorum libri Aecjusza z Amidy. Przyrządzano je z czterech części skammonii ${ }^{24}$ i 50 ziarnek pieprzu, które razem rozdrabniano i mieszano z trzema częściami garum. Gdy mikstura była gotowa, można ją było serwować jako embamma ${ }^{25}$. Z tekstu dowiadujemy się, że takie garum skutecznie usuwało żółć z organizmu.

Sosem, którego składnikami było garum i oliwa, było garelaium ( $\gamma \alpha \varrho \varepsilon ́-$ $\lambda \alpha \iota v v)$. Taką definicję tej mikstury podał Hesychios ${ }^{26}$. Zapewne istniały różne odmiany tego dodatku. Galen zachował pewien wyszukany przepis dla smakoszy. Sos składał się z garelaium, odrobiny wina oraz wątroby ryby trigle $(\tau \varrho i \gamma \lambda \eta)^{27}$. Do naczynia wlewano składniki płynne i wrzucano rozdrobnioną wątróbkę. Następnie nadawano mieszaninie jednolitą konsystencję ${ }^{28}$. Przyrządzone (zapewne pieczone ryby) jedzono maczając je w tym sosie.

Znamy również kilka innych zastosowań garelaium. Źródła informują nas bowiem, iż używano go jako przyprawy do kapusty. Tę ostatnią gotowano w wodzie do miękkości (nie wolno jednak było jej rozgotować), a potem

${ }^{22}$ Np. Galeni de alimentorum facultatibus libri, s. 725-726, w: Claudii Galeni opera omnia, ed. D.C.G. Kühn, VI, Lipsiae 1823, (dalej-Galenus, De alimentorum facultatibus, Kühn VI).

${ }^{23}$ Por. Pedanii Dioscuridis Anazarbei liber II 32, 1, 1-4, w: Pedanii Dioscuridis Anazarbei de materia medica libri quinque, ed. M. Wellmann, vol. I-III, Berolini 1906-1914; Galeni de simplicium medicamentorum temperamentis et facultatibus libri s. 377, w: Claudii Galeni opera omnia, ed. D.C.G. Kühn, XI-XII, Lipsiae 1826-1827; Aetius Amidenus, Iatricorum libri II 150, 1-3; Pauli Aeginetae liber VII 3, 3, 21-23, w: Paulus Aegineta, ed. I.L. Heiberg, I-II, Lipsiae - Berolini 1921-1924.

${ }^{24}$ Convolvulus scammonia - gatunek powoju używany dość powszechnie w medycynie greckiej jako substancja oczyszczająca. Charakterystykę właściwości tejże rośliny por. np. Aetius Amidenus, Iatricorum libri III 25, 1-14.

25 Por. Aetius Amidenus, Iatricorum libri III 83, 1-2.

${ }^{26}$ Por. Hesychii Alexandrini lexicon, post I. Albertum rec. M. Schmidt, I-V, Ienae 1859-1868, g, garšlaion, 176, 1.

27 Barwena, por. Kokoszko, Ryby, s. 358-367.

28 Galenus, De alimentorum facultatibus, Kühn VI, s. 716. Z punktu widzenia sposobu podania garelaium opisane przez Galena powinno być zaliczone do kategorii embamma. 
gorącą wkładano do garelaium i podawano ${ }^{29}$. Z garelaium podawano także surowe warzywa. Zapewne w takim przypadku sos ten spełniał rolę swoistego dressing $u^{30}$. Tak przyrządzone jarzyny miały właściwości przeczyszczające, zwłaszcza jeżeli zostały spożyte przed zasadniczym posiłkiem. Wiemy także, że garelaium było dodawane do świeżych, surowych jajek. Wybijano je i mieszano $\mathrm{z}$ omawianym $\operatorname{sosem}^{31}$. Tej ostatniej potrawie również przypisywano pozytywny wpływ na wydalanie produktów trawienia ${ }^{32}$.

Aecjusz z Amidy wzmiankuje jeszcze jeden sos, który oparty był na garum i mógł mieć zastosowanie kulinarne. Chodzi mianowicie o oenogarum, oinogaron (oivó $\alpha \propto \varrho o v)$. Składało się ono z garum i wina. Jak wynika z przepisu podanego przez rzeczonego medyka, sporządzając oenogarum używano dwu części sosu rybnego na jedną część wina. Rodzaj tego ostatniego nie był zapewne ważny, gdyż Aecjusz go nie specyfikuje. By dodać mieszaninie nieco słodyczy dolewano miód ${ }^{33}$. Choć w analizowanych źródłach brak szczegółów dotyczących zastosowania kulinarnego oenogarum, można się jednak domyślać, iż serwowano je jako embamma lub katachysma. Analogii dostarczają inne sosy z grupy garum.

Wersja oenogarum znana z Iatricorum libri zawiera szereg dodatkowych składników. Z kontekstu wynika, iż były one dorzucone w celu uzyskania przez ten sos pożądanych właściwości terapeutycznych, a dokładniej oczyszczających. Dlatego też Aecjuszowy specyfik zwie się oenogarum oczyszczającym, oinoga-

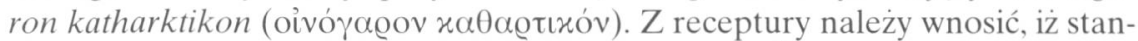
dardowo dorzucano do właściwego oenogarum pieprz ${ }^{34}$ i lubczyk, a opcjonalnie

${ }^{29}$ Oribasii collectionum medicarum liber III 29, 3, 1-4, w: Oribasii collectionum medicarum reliquiae, ed. I. Raeder, I-IV, Lipsiae - Berolini 1928-1933. Orybazjusz jest kolejnym autorem medycznym, kluczowym dla rekonstrukcji dziejów sztuki kulinarnej. Na jego temat por. Kokoszko, Ryby, s. 14-15.

${ }^{30}$ Poprzez dressing rozumiem zimny sos podany osobno lub dodawany do potraw (najczęściej sałatek warzywnych).

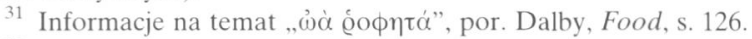

32 Oribasius, Synopsis 'd Eustathium filium IV 28, 17, 1-2,w: Oribasii synopsis ad Eustathium filium et libri ad Eunapium, ed. J. Raeder, Lipsiae 1926.

${ }^{33}$ Miód w takich przepisach zazwyczaj musiał spełniać wysokie wymagania, por. np. Galeni de sanitate tuenda libri, s. 270-271, w: Claudii Galeni opera omnia, ed. D.C.G. Kühn, VI, Lipsiae 1823. Typowa charakterystyka bizantyńska: Aetius Amidenus, Iatricorum libri I 273, 1-15. Wybrana literatura nowożytna: Dalby, Food, s. 179-180; E. Crane, The Archaeology of Beekeeping, London 1983, passim; taż, The World History of beekeeping and honey hunting, passim; J. E. Jones, Hives and Honey of Hymettus, ,Archaeology” 29 (1976), 80-91; Stobart, Herbs, s. 89-90.

34 Zapewne chodzi o pieprz czarny (Piper nigrum). Użycie innego gatunku tej przyprawy było zwykle sygnalizowane przez dodanie przydawki. Typowa charakterystyka bizantyńska: Aetius Amidenus, Iatricorum libri I 316, 1-5. Wybrana literatura nowożytna: André, L'alimentation, s. 209; Bremness, Wielka księga ziót, s. 94; A. Dalby, Empire of pleasures. Luxury and Indulgence in the Roman World, London - New York 2000, 43 i 89-94; Dalby, Food, s. 254-255; Dalby Grainger, The Classical Cookbook, s. 137 i 250; Solomon, The Apician Sauce, s. 115-131; Sto- 
skammonię (dla usunięcia z organizmu żółci), szafran (w celu pozbycia się flegmy) lub paprotkę ${ }^{35}$ (jeśli celem użycia tego oenogarum było pozbycie się czarnej żółci).

Kolejny sos uzyskiwany z garum, mianowicie oksygarum, oksygaron

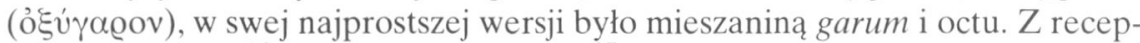
tur Orybazjusza ${ }^{36}$ i Aecjusza z Amidy ${ }^{37}$ wynika, iz łączono je w równych proporcjach. Nie ma bezpośrednich wskazań, iż dwuskładnikowe oksygarum wymagało gotowania. Receptury na bardziej skomplikowane odmiany tego sosu sugerują jednak taką metodę.

Dysponujemy kilkoma przepisami na oksygarum. Dwa implikują jego zastosowania kulinarne i terapeutyczne, a dwa kolejne sugerują przeznaczenie sosu jako przede wszystkim dodatku do potraw. Para receptur pochodząca z pism medycznych (Orybazjusza i Aecjusza z Amidy) jest podobna, chociaż nie identyczna, a działanie terapeutyczne specyfików określone już w samych tytułach receptur. Jedno i drugie nazwane zostało oksygarum oczyszczającym,

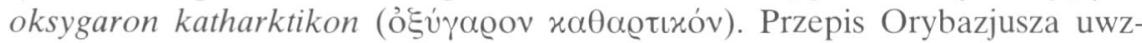
ględnia skammonię, pieprz, imbir, miętę, nasiona selera, ocet, garum oraz miód. Przepis Aecjusza z Amidy z kolei zawiera nasiona selera, pieprzu, kminku zwyczajnego ${ }^{38}$, sok zapaliczki cuchnącej ${ }^{39}$, skammonię i równe części garum i octu. Z receptury wynika też, że zamiast skammonii, można było dodać szafranu lub paproci ${ }^{40}$.

bart, Herbs, s. 140-150; J. M. Welch, The Spice Trade. A Bibliographic Guide to Sources of Historical and Economic Information, Connecticut - London 1994, 9-40.

35 Polypodium vulgare.

36 Por. Oribasius, Collectionum medicarum eclogae medicamentorum 79, 12, 1-13, 1, w: Oribasii collectionum medicarum reliquiae, vol. IV, libros XLIX-L: Libros incertos, eclogae medicamentorum, indicem continens, ed. I. Raeder, Lipsiae - Berolini 1933.

${ }^{37}$ Por. Aetius Amidenus, Iatricorum libri III 87, 1-5

${ }^{38}$ Cuminum cyminum. Typowa bizantyńska charakterystyka tej rośliny: Aetius Amidenus, Iatricorum libri 235, 1-3. Wybrana literatura nowożytna: André, L'alimentation, Paris 1961, s. 203: Bremness, Wielka księga ziót, s. 62; D. R. Brothwell, Foodstuffs, Cooking, and Drugs, w: Civilization of the Ancient Mediterranean. Greece and Rome, I, ed. M. Grant - R. Kitzinger, New York 1987, 252 i 260; Dalby, Food, s. 74 i 108-109; Dalby - Grainger, The Classical Cookbook, s. 139; Stobart, Herbs, s. 67-68; D. Zohary - M. Hopf, Domestication of Plants in the Old Worlds. The Origin and Spread of Cultivated Plants in West Asia, Europe and the Nile Valley, Oxford 1993, 189. Muszę przyznać się do popełnienia błędu w mojej książce o rybach. Kmin rzymski (Carum carvi) był tam niekiedy mylony z kminkiem zwyczajnym (Cuminum cyminum).

${ }^{39}$ Ferula assafoetida. Substancje z niej otrzymywane były najczęściej zwane silfion ( $\sigma$ i $\left.\lambda \phi \iota \mathrm{v}\right)$ lub opos Kyrenaikos (Kvọvaıxò ỏ ós). Charakterystyka tej substancji, por. np. Aetius Amidenus, Iatricorum libri I 361-365. Podstawowa literatura na ten temat: A.C. Andrews, The Silphium of the Ancients. A Lesson in Crop Control, ,Isis” 33 (1941) 232-236; A. Arndt, Silphium, w: Spicing up the Palate. Proceedings of the Oxford Symposium on Food and Cookery, London 1992, 28-35; Dalby, Food, s. 29, 42, 303-304; D. Roques, Médecine et botanique. Le silphion dans l'œuvre d'Oribase, ,Revue des Ėtudes Grecques” 106 (1993) 380-399; Kokoszko, Ryby, s. 387.

40 Typowa charakterystyka tej rośliny: Aetius Amidenus, Iatricorum libri I 331, 1-2. 
Oksygarum w De re coquinaria występuje w dwu wariantach. Pierwszy z nich przewidywał pół uncji ${ }^{41}$ pieprzu, trzy scripula ${ }^{42}$ żebrzycy pokręconej ${ }^{43}$, sześć scripula kardamonu malabarskiego ${ }^{44}$, sześć scripula kminku zwyczajnego, jedno scripulum liści lauru ${ }^{45}$, sześć scripula suszonej mięty, miód, garum i ocet. Wszystkie składniki stałe należało utrzeć, przesiać i wymieszać z miodem, a potem dodawano do nich garum i ocet ${ }^{46}$. Druga wersja przepisu była znacznie prostsza i uwzględniała uncję pieprzu, po jednej uncji pietruszki, kminu rzymskiego ${ }^{47}$ i lubczyku ogrodowego, miód, garum i ocet ${ }^{48}$.

Oksygarum podawano do potraw mięsnych i ryb. Galen, na przykład, pisał

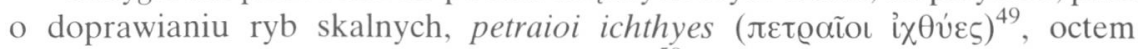
i garum, oraz o posypywaniu ich pieprzem ${ }^{50}$. Miał on, być może, na myśli jakąś (nieskomplikowaną) formę oksygarum. W każdym razie to ostatnie byłoby $\mathrm{z}$ pewnością świetnym zamiennikiem przypraw wymienionych przez słynnego lekarza. Ten sam twierdził także, iz oksygarum dodawano przy przyrządzaniu warzyw strączkowych ${ }^{51}$. Te ostatnie wpierw moczono w wodzie, potem gotowano do miękkości, a następnie doprawiano garum, oksygarum lub jedynie solą.

Refleksje te należy zakończyć stwierdzeniem, iż oksygarum przypisywano pewne konkretne właściwości dietetyczne. Z Iatricorum libri wynika, iż oczyszczające oksygarum w wersji ze skammonią usuwało żółć. Gdy zamiast tej ostatniej dodano szafranu, powstała mikstura przyczyniała się do wydalania

${ }^{41}$ Pół uncji $=27,288$ grama.

42 Trzy scripula $=1,137$ grama.

43 Seseli tortuosum, por. Kokoszko, Ryby, s. 390.

44 Amomum cardamomum. Typowa charakterystyka bizantyńska: Aetius Amidenus, Iatricorum libri I 182, 1-4. Wybrana literatura nowożytna: André, L'alimentation, s. 209-210; Apicius, De re coquinaria, s. 263, nota 64; Dalby, Food, s. 74; J. Koder, Gemüse in Byzanz. Die Versorgung Konstantinopels mit Frischgemüse im Lichte der Geoponika, Wien 1993, 48-49; J. I. Miller, The Spice Trade of the Roman Empire, Oxford 1969, 71-73; Stobart, Herbs, s. 47-48; Welch, The Spice Trade, s. 9-40; por. także Kokoszko, Ryby, s. 375.

${ }^{45}$ Laurus nobilis, inaczej liście bobkowe. Typowa charakterystyka bizantyńska: Aetius Amidenus, Iatricorum libri I 89, 1-5. Wybrana literatura nowożytna: André, L'alimentation, s. 204; Brothwell, Foodstuffs, s. 252; Dalby, Food, s. 48-49; por. także Kokoszko, Ryby, s. 377.

${ }^{46}$ Por. Apicius, De re coquinaria I $34,1$.

47 Carum carvi. Typowa charakterystyka bizantyńska: Aetius Amidenus, Iatricorum libri I 183, 1-4. Wybrana literatura nowożytna: Dalby, Food, s. 74; Dalby - Grainger, The Classical Cookbook, s. 108; Gozzini Giacosa, A Taste of Ancient Rome, s. 15-16; Leksykon roślin, s. 210-211; V. Nutton, Galen and the Traveller's Fare, w: Food in Antiquity, ed. J. Wilkins - D. Harvey M. Dobson, Exeter 1995, 364; Stobart, Herbs, s. 46-47; por. także Kokoszko, Ryby, s. 376.

${ }^{48}$ Por. Apicius, De re coquinaria I 34, 2.

49 Termin „ryby skalne” oznaczał niewielkie, zwykle kolorowe ryby morskie, żyjące blisko brzegu, między skałami w płytkich wodach przybrzeżnych. Należą one do Labridae (wargacze), por. Kokoszko, Ryby, s. 253-254.

${ }^{50}$ Por. Galenus, De alimentorum facultatibus, Kühn VI, s. 725.

51 Por. tamże s. 534-535. 
z organizmu flegmy. W końcu, jeśli oksygarum sporządzono z dodatkiem paproci, sos ten sprzyjał pozbywaniu się czarnej żółci ${ }^{52}$.

Zaprezentowany materiał dowodzi, iż kuchnia grecka dysponowała licznymi ingrediencjami, które istotnie wpływały na smak podawanych produktów żywnościowych. Czyniły one potrawy nie tylko urozmaiconymi, ale także wyszukanymi. Z przytoczonych danych wynika, iz cała ich grupa uwzględniała w swoim składzie garum. Niestety, w analizowanych materiałach brak szczegółów przyrządzania niektórych wzmiankowanych dodatków. Najwięcej wyczerpujących informacji w tym względzie przynoszą pisma medyczne. Receptury zawarte w tych ostatnich pozwalają domniemywać, iż opisywane dodatki sporządzane były nie tylko dla ich walorów smakowych, ale także ze względu na ich wartości regulujące bądź lecznicze.

\section{SAUCES IN GREEK CUISINE. GARUM AND GARUM-BASED SAUCES}

(Summary)

The present article deals with recipes, culinary uses and therapeutic applications of garum and other garum-based sauces as described in sellected (Athenaeus of Naucratis, Pedanius Dioscurides, Galen, Oribasius, Aetius of Amida, Paul of Aegina, Geoponica and Byzantine lexica) Greek literary sources.

The author of the article starts his analysis with garum (quoting predominantly the Geoponica) to proceed to elaborate on a digestive called garos katharktikon ( $\gamma \alpha \dot{\varrho} \varrho \varsigma x \alpha \theta \alpha \varrho \tau \iota x o ́ v)$ (preserved by Aetius of Amida), subsequently on garelaium, garelaion ( $\gamma \alpha \varrho \varepsilon ́ \lambda \alpha \iota v)$ (as presented by Galen, Hesychios and Oribasius), then on oenogarum, oinogaron (oivóya@ov) (on the basis of the doctrines included in the Iatricorum libri by Aetius of Amida) to finish by characterizing oxygarum, oxygaron (ógúragov) (in connection with the data extant in the works by Galen, Oribasius, Aetius of Amida and De re coquinaria). On the way, the author identifies some ingredients (herbs, spices and other additives) quoted in the aforementioned recipes.

The author concludes that Greek cuisine had at its disposal a variety of ingredients which would modify and add to the final flavor as well as value of a dish.

52 Na temat teorii czterech humorów oraz znaczenia poszczególnych terminów por. M. Kokoszko, Descriptions of Personal Appearance in John Malalas' Chronicle, Byzantina Lodziensia 2, Łódź 1998, 22. tenże, Nauka antyczna a opisy portretowe w dziełach Prokopiusza z Cezarei, „Eos” 87 (2000), 255-277, spec. 261-266; tenże, Skąd brać rekruta do armii i dlaczego? Antyczna nauka wyjaśniająca sugestie Wegecjusza zamieszczone w dziele „Epitoma rei militaris”, „Piotrkowskie Zeszyty Historyczne" 3 (2001), 11-29, spec. 21-24. 
Combined together, they gave the Greek cuisine of antiquity and Byzantium a mouth-watering touch of sophistication. He also opines that these are the medical sources which are crucial to the reconstruction of both the recipes as well as the applications of the described concoctions. Finally, he comes to the conclusion that the discussed in the article foods were made use of not only for their culinary values but also with an eye to profiting from their healing properties. It is the latter feature of sauces that emerges with a striking clarity and strength from the medical treatises. 